\title{
INTRODUCING FLEXIBLE RETIREMENT: A DYNAMIC MODEL
}

\section{András Simonovits ${ }^{\mathrm{a}}$}

\begin{abstract}
Mature market economies steadily raise full-benefit retirement ages and add flexible (or variable) retirement age: early/late retirement is punished/rewarded to neutralize the budgetary impact of free choice within wide age limits. New EU member states also raise full-benefit retirement ages, but typically restrict downward flexibility, conditioning it on long enough length of contribution (e.g., Czechia) but sometimes even forsake the deduction (Females40 scheme in Hungary). In this paper, we shall study the costs of removing restrictions on flexibility. In our dynamic model, we show that even if early retirement is duly punished, diminishing the effective retirement age by 1 year raises the first year's and the total expenditures during transition by $8 \%$ and $70 \%$ of the original annual expenditures, respectively.
\end{abstract}

Keywords: Retirement age, flexible retirement age, variable retirement age, transition costs

\section{JEL Classification: H11, H55}

\section{Introduction}

Since the 1990s, in the developed countries, there has been a tendency to raise the fullbenefit (normal, statutory, etc.) retirement age (FRA for short) in parallel with the rising life expectancy. This measure in itself is futile if the effective retirement age does not increase similarly (Gruber and Wise, 1999; Chlon-Dominczak et al., 2021). Considering new EU member states, Gál and Radó (2020, Figure 16.5) demonstrated that in the bulk of the foregoing countries, the two ages grew in parallel between 1996/2000 and 2014, easing the public burden.

* I acknowledge the help of Stefan Domonkos, Gábor Kézdi, Attila Széphelyi and two anonymous referees. A previous version of the paper was published as a Working Paper under the same title with the Institute of Economics, Budapest.

a Institute of Economics, Centre for Economic and Regional Studies, Budapest, Hungary Email: simonovits.andras@krtk.elkh.hu 
According to economic theory (see Appendix), the best method to achieve such a parallel increase is to introduce an actuarially fair benefit/retirement age schedule: if a worker retires earlier/later than normal, then his/her annual benefit is decreased/ increased so that his/her lifetime net contribution remains 0 . The simplest fair method is the so-called Nonfinancial Defined Contribution (NDC, e.g., in Sweden; see Section 2), but other methods work similarly well. These methods combine efficiency and fairness, though self-criticism has recently emerged concerning the neglect of the strong positive correlation between life expectancy and lifetime earnings (e.g., Breyer and Hupfeldt, 2009; Holzmann et al., 2020).

In contrast, several new EU member states have made arbitrary conditions on early retirement (see the European Commission, 2021, for details). In Czechia, only those workers are allowed to retire before reaching the FRA who have at least 35 years of contributions and even they are severely punished (OECD, 2020, pp. 2-29, and Section 2). In Slovakia, there is a condition for early retirement: the initial benefit be at least as high as the minimum wage, approximately equalling the average pension benefit of the year. The Polish retirement age policy is controversial; for example, the effective retirement age frequently falls below the minimum age (Chlon-Dominczak, 2019, and Section 2).

Hungary has been operating a dual, loose/rigid system since 2011. Firstly, every female is allowed to retire without any benefit reduction if she has acquired at least 40 years of entitlement (correlated but not identical to years of contributions). Secondly, nobody else is allowed to retire, even with reduced benefits, until she/he reaches the FRA, increasing otherwise quite fast: 62 (2013), 63 (2016), 64 (2019) and 65 (2022). Such a system is unfair to the excluded majority and socially suboptimal. To see this, consider two females in 2022: one is 64 years old and has 39 years of entitlement; she has to wait another year to retire. The other is only 60 years old but has 40 years of entitlement; therefore, she can retire without any other limitation and draw full benefits for another 5 years, when she reaches her FRA (and after).

Each of these systems applies too strict/loose requirements and diminishes social welfare with respect to a truly flexible system. Among new member states, only Estonia appears to have adopted an unrestricted flexible retirement system, but it keeps the benefits rather low (Soosar et al., 2021), implying late retirement (Table A2).

Why are such restrictive systems in force at all? Probably the foregoing governments do not trust market incentives keeping average retirement age close to the FRA and they prefer positive discrimination. Though we support the introduction of genuinely flexible retirement, we list four problems with it. (i) The bulk of the workers do not know the rules, and eventually a large part might opt for continued work if they knew the rules (Gustman and Steinmeier, 2005; Bottazzi et al., 2006; Barr and Diamond, 2008, Section 4.7; 
Benitez-Silva et al., 2009). (ii) Even if workers knew the rules, they would retire at the earliest age (Barr, 2006). (iii) The healthier workers retire later and live longer, so they gain, while others lose (Fabel, 1994; Diamond, 2003; Eső and Simonovits, 2002; Simonovits, 2006; Eső et al. (2011), etc.). (iv) If we replace the rigid retirement age, but fix the contribution rate, temporary deficits arise. These factors frequently strengthen each other: for example, due to the recent real wage explosion and price indexation of benefits in progress in Hungary, early retirees lose with respect to late retirees but they cannot help themselves, due to (i) and (ii) (Simonovits, 2019).

In this paper, we shall confine our attention to issue (iv). Using very strong homogeneity assumptions on demography and economy, we show that if all workers can and do retire at 64 rather than 65 , then by raising their time spent in retirement from 16 to 17 years, the temporary and the total costs of this reform are equal to 8 and $70 \%$ of the pre-reform one-year expenditures, respectively. (In the simplest static model, the welfare gain is equal to $0.4 \%$; see Table A1.) If we relaxed our very strong assumptions, the results would change quantitatively. We only modify one assumption: it is the growth rate rather than the level of the real wage which is time invariant. The previous results remain qualitatively valid but change quantitatively: the discounted total costs in terms of annual expenditures drop from 0.7 to 0.49 as the annual growth rate rises from 0 to $4 \%$. Of course, the costs of the reform can be reduced by the elimination of exemptions such as Females 40 but it is politically risky.

The structure of the paper is as follows. Section 2 presents retirement regimes in various EU countries. Sections 3 and 4 discuss the replacement of the rigid system with a flexible one for time-invariant and growing average real wages, respectively. Section 5 draws the conclusions. An Appendix analyses the welfare impact of a flexible system.

\section{Various Retirement Regimes in EU}

In this section, we review the experience of a truly flexible retirement system in Sweden, and partially flexible ones in Hungary, Czechia and Poland.

Palmer and Könberg (2020, pp. 30-32) described the Swedish system as satisfactory. The starting point is the pioneer NDC (Nonfinancial Defined Contribution), which almost directly implies flexibility. There is no need for a FRA but to limit the use of supplementary pension received by poorer pensioners, nobody can rely on it below 65. For a long period, the earliest retirement age has been 61 years, below which only disability pension was available. There has been another, upper limit: 67 years, where the employer can fire the worker freely. At the end of 2017, the six democratic parties agreed to raise the retirement ages: to lift the minimum retirement age from 61 to 64 years in three steps between 2020 and 2026; the threshold of supplementary benefit, 65, is raised to 66 years; 
and the threshold of free firing from 67 to 69 , both in two steps. The fast rise of the minimum age, however, may represent dissatisfaction with the stagnating effective retirement age.

At the start of the reform (around 2000), 90\% of the Swedes retired before or at 65 years; this value is still $80 \%$ but the average has remained at 65 . In the 1950 cohort, $28 \%$ retired before $65,50 \%$ at age 65 and $22 \%$ after 65 . To a certain degree, the choice of the retirement age is rational. For example, workers with lower skills, whose life expectancies are lower, retire as early as possible.

The following question arises: to what extent does the DC system influence the retirement decision? As background information, we note that the effective retirement age sank all over the world between 1970 and 1990. The Swedish reform contributed to a reversion of the process.

In Hungary, between 2001 and 2007, the female FRA - originally 5 years below the male counterpart - grew quite steeply, from 58 to 61 years but due to the weak incentives, the effective retirement age oscillated around 57.5 years. Due to strengthened incentives, in 2009 , the female FRA reached 62, while the effective retirement age jumped to 60 years.

Table 1: Full and effective retirement ages and size of retiring cohorts

\begin{tabular}{l|c|c|c|c|c|c|c}
\hline \multirow{2}{*}{ Year } & \multirow{2}{*}{$\begin{array}{c}\text { Full } \\
\text { retirement } \\
\text { age (yr) }\end{array}$} & \multicolumn{2}{|c|}{ Females40 } & \multicolumn{2}{c|}{ Females total } & \multicolumn{2}{c}{ Males } \\
\cline { 3 - 8 } & Effective & $\begin{array}{c}\text { Size } \\
\text { (’000) }\end{array}$ & $\begin{array}{c}\text { Effective } \\
\text { age (yr) }\end{array}$ & $\begin{array}{c}\text { Size } \\
\text { (‘000) }\end{array}$ & $\begin{array}{c}\text { Effective } \\
\text { age (yr) }\end{array}$ & $\begin{array}{c}\text { Size } \\
\text { (’000) }\end{array}$ \\
\hline $\mathbf{2 0 1 1}$ & 62.0 & 57.6 & 54.8 & 58.5 & 84.9 & 60.3 & 43.2 \\
\hline $\mathbf{2 0 1 2}$ & 62.0 & 57.8 & 26.6 & 59.2 & 51.0 & 61.8 & 21.0 \\
\hline $\mathbf{2 0 1 3}$ & 62.0 & 58.0 & 24.0 & 59.6 & 40.0 & 62.2 & 21.6 \\
\hline $\mathbf{2 0 1 4}$ & 62.5 & 58.3 & 27.5 & 59.6 & 38.9 & 62.8 & 18.9 \\
\hline $\mathbf{2 0 1 5}$ & 62.5 & 58.7 & 28.6 & 60.0 & 41.6 & 62.7 & 22.2 \\
\hline $\mathbf{2 0 1 6}$ & 63.0 & 59.0 & 28.3 & 61.1 & 55.9 & 63.1 & 22.6 \\
\hline $\mathbf{2 0 1 7}$ & 63.5 & 59.3 & 28.7 & 61.0 & 46.9 & 63.6 & 32.3 \\
\hline $\mathbf{2 0 1 8}$ & 63.5 & 59.6 & 29.0 & 61.2 & 49.6 & 63.7 & 35.0 \\
\hline $\mathbf{2 0 1 9}$ & 64.0 & 59.6 & 27.6 & 62.0 & 59.6 & 64.1 & 57.0 \\
\hline
\end{tabular}

Source: Based on Fazekas et al. (2020), Table 11.5, p. 240

Since 2011, there has been a radical change in pension policy: rigid and rising effective retirement age with large exceptions in Females40. Table 1 presents the pertinent statistics of the Hungarian old-age retirement system for 2011-2019. Notwithstanding 
the unification of male and female FRAs, the practice of Females40 requires the separation of the two genders, and among the females, favoured and not-favoured as well. As can be seen, in each category, the average retirement age has been increasing and the size of the retiring cohorts has been oscillating. While in 2019, the FRA was already 64 years for those born in 1955, and the average (i.e., effective) male retirement age surpassed it slightly, the average Females 40 retirement age was lower by 4.4 years and the total female average remained at 62 years in 2019.

Turning to the Czech retirement age policy (see OECD, 2020, for a critical analysis), note that it is flexible but the conditions are very stringent: the worker claiming pension has to work at least 35 years before reaching the FRA, and the reduction is very severe (e.g., for retiring 5 years earlier, the reduction is equal to $43 \%$ in contrast to the theoretical value of $33.3 \%$ in Table 3). Figures 1 and 2 show the distributions of retirees according to years of contribution: Figure 1 for FRA, Figure 2 for early retirees. Note that both distributions are concentrated at very high values.

Figure 1: Distribution of new retirees with respect to years of contribution, FRA, Czechia

A. Normal earnings-related pension

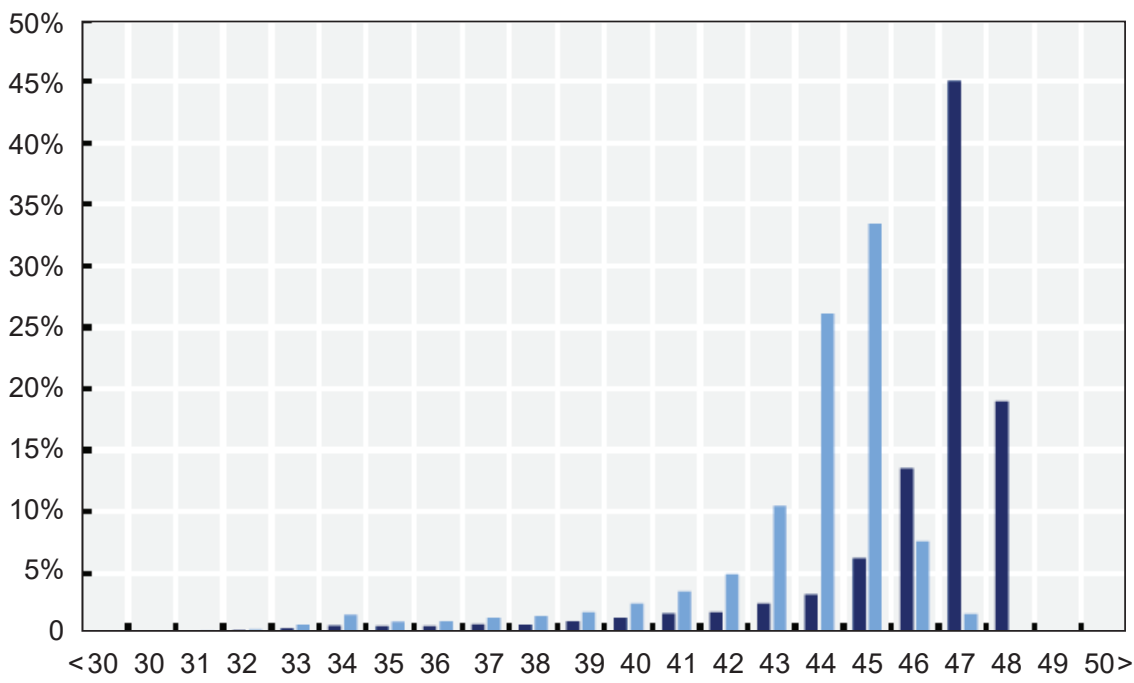

Men Women

Source: Figure 1.12 (OECD, 2020, p. 27) 
Figure 2: Distribution of new retirees with respect to years of contribution, early, Czechia

B. Early earnings-related pension

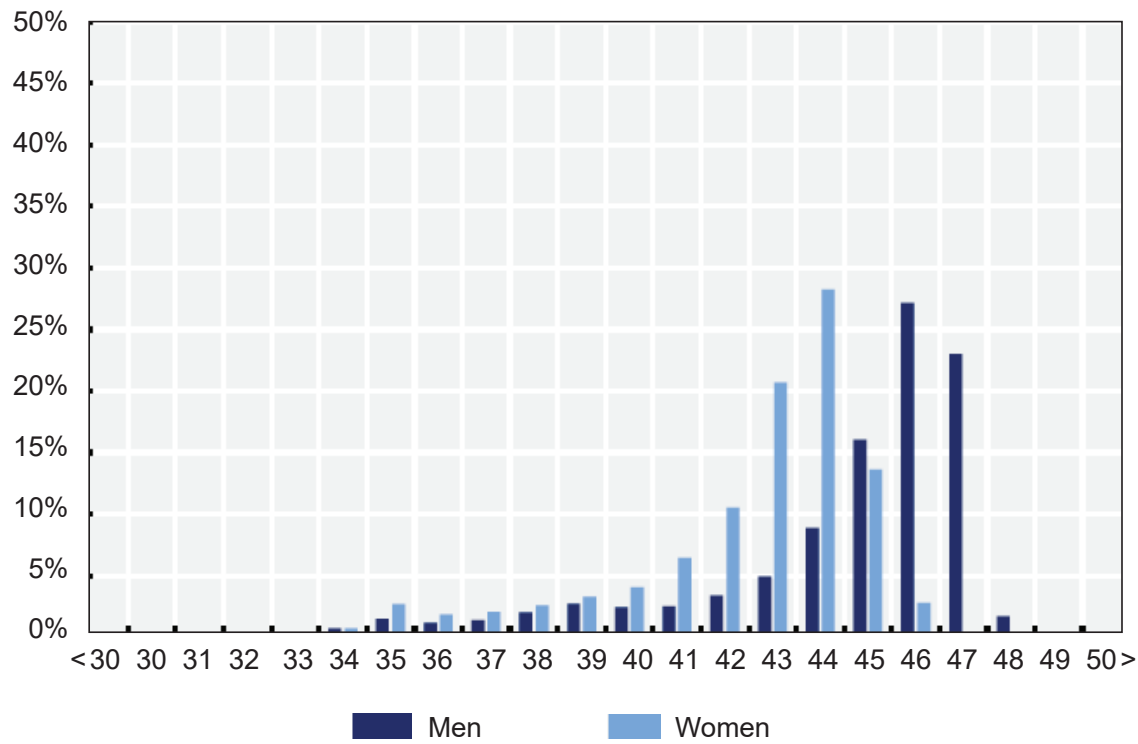

Source: Figure 1.12 (OECD, 2020, p. 27)

Table 2: Peaks and troughs in effective male and female retirement ages and durations, Poland

\begin{tabular}{l|c|c|c|c}
\hline \multirow{2}{*}{ Year } & \multicolumn{2}{|c|}{ Male } & \multicolumn{2}{c}{ Female } \\
\cline { 2 - 5 } & $\begin{array}{c}\text { Effective } \\
\text { retirement age }\end{array}$ & $\begin{array}{c}\text { Retirement } \\
\text { duration }\end{array}$ & $\begin{array}{c}\text { Effective } \\
\text { retirement age }\end{array}$ & $\begin{array}{c}\text { Retirement } \\
\text { duration }\end{array}$ \\
\hline $\mathbf{1 9 9 0}$ & 58.5 & 16.0 & 55.8 & 23.3 \\
\hline $\mathbf{1 9 9 7}$ & 58.3 & 17.4 & 54.1 & 25.9 \\
\hline $\mathbf{2 0 0 3}$ & 60.5 & 17.1 & 56.7 & 23.7 \\
\hline $\mathbf{2 0 1 0}$ & 62.0 & 16.2 & 53.8 & 23.0 \\
\hline $\mathbf{2 0 1 3}$ & 59.7 & 18.7 & 59.5 & 23.5 \\
\hline $\mathbf{2 0 1 7}$ & 64.6 & 15.9 & 61.0 & 23.8 \\
\hline
\end{tabular}

Source: Chlon-Dominczak (2019, Figure 2) 
Turning to Poland, this country has had rather high male and female FRAs since 1954: 65 for males and 60 for females, respectively. The earliest retirement ages, however, were 5 years lower and the actual ones even lower. The relatively low life expectancies had been stagnating until the 1990s. Due to the mass unemployment during the transition period, effective retirement ages dropped before they started increasing. As late as 2012, the male effective retirement age was as low as 59.7 years, and the female counterpart was 53.8 years in 2010 . Since then, both effective retirement ages have been increasing, to 64.6 and 61.0 , respectively, stabilizing the retirement duration. Table 2 displays the corresponding statistics.

Having analysed the empirics of flexible and inflexible retirement, we turn to the dynamic modelling of transition from the latter to the former.

\section{Model with Time-invariant Real Wage}

In our models of transition from rigid to flexible retirement, we assume that there is no inflation, the population is stationary, the life expectancy and the total fertility rate are time-invariant, and each cohort is represented by a single person. In the basic model, we also apply an additional assumption: the (average) real wage is time-invariant. First, we analyse a static (or steady-state) model, then we turn to a dynamic one. To avoid complications, we assume that certain events occur on 31 December of the corresponding year.

\subsection{Static model}

To prepare the ground, we consider a static model here (see Simonovits, 2003, Chapter 12). Our representative worker starts to work at age $Q$, works until age $R$, while earning a wage $w$ (including all pension contributions), his/her contribution rate is equal to $\tau$ in $(0,1)$ and after retiring, he/she dies at age $D: 0<Q<R<D$. Benefits in progress are equal to initial benefits. For later use, we introduce the number of contributive years: $S=R-Q$ and the duration in retirement: $T=D-R$. The benefit is equal to the ratio of the lifetime contributions to the remaining life expectancy:

$$
b(R)=\frac{\tau S w}{T}, \quad S=R-Q, \quad T=D-R .
$$

In this system, the lifetime net contribution $z(R)$ is equal to 0 . In fact, substituting $b(R)$ into

$$
z(R)=\tau S w-b(R) T
$$

a simple calculation yields $z(R)=0$. This is true, regardless of the variance of the wage $w$, retirement age $R$ and age at death $D$. 
At the individual and governmental levels, however, the value of $D$ is unknown; therefore, we have to calculate with an expected value in (1). From now on, we assume that $Q$ and $D$ are identical but $R$ can vary within an appropriately chosen interval $R_{\mathrm{m}} \leq R \leq R_{\mathrm{M}}$.

Assuming a total wage compensation $w$ and a contribution rate $\tau=0.2$, hence neglecting healthcare contributions and personal income taxes - the net wage is defined as $u=(1-\tau) w$. In the pension literature, it is customary to relate benefits to net wages; their ratio is called the net replacement rate. As an illustration, Table 3 displays how this replacement rate varies in the flexible system when the retirement age varies as $R=60, \ldots, 70$, while $Q=25$ and $D=81$. It is evident how low the earliest net replacement rate is and how high the maximum delayed one is, both with respect to the normal one. In addition, we present the accumulated proportional modifications, which are strongly asymmetric.

Table 3: Retirement age and replacement rate

\begin{tabular}{c|c|c|c|c|c}
\hline $\begin{array}{c}\text { Retirement } \\
\text { age }(\mathbf{y r})\end{array}$ & $\begin{array}{c}\text { Replacement } \\
\text { rate }\end{array}$ & $\begin{array}{c}\text { Accumulated } \\
\text { modification }\end{array}$ & $\begin{array}{c}\text { Retirement } \\
\text { age (yr) }\end{array}$ & $\begin{array}{c}\text { Replacement } \\
\text { rate }\end{array}$ & $\begin{array}{c}\text { Accumulated } \\
\text { modification }\end{array}$ \\
\hline $\boldsymbol{R}$ & $\boldsymbol{b}(\boldsymbol{R}) / \mathbf{u}$ & $\boldsymbol{b}(\boldsymbol{R}) / \boldsymbol{b}(\mathbf{6 5})-\mathbf{1}$ & $\boldsymbol{R}$ & $\boldsymbol{b}(\boldsymbol{R}) / \mathbf{u}$ & $\boldsymbol{b}(\boldsymbol{R}) / \boldsymbol{b}(\mathbf{6 5})-\mathbf{1}$ \\
\hline 60 & 0.417 & -0.333 & 66 & 0.683 & 0.093 \\
\hline 61 & 0.450 & -0.280 & 67 & 0.750 & 0.220 \\
\hline 62 & 0.487 & -0.221 & 68 & 0.827 & 0.323 \\
\hline 63 & 0.528 & -0.156 & 69 & 0.917 & 0.467 \\
\hline 64 & 0.574 & -0.075 & 70 & 1.023 & 0.636 \\
\hline 65 & 0.625 & 0 & - & - & - \\
\hline
\end{tabular}

Source: Own calculations

\subsection{Dynamic model}

We now turn to the simplest dynamic model. We still assume that each cohort is represented by one person and they start working and die at the same age. The only change appears with the reduced retirement age. The calendar years are denoted by $t=0,1,2, \ldots$.

To simplify the calculations, we need a complementary assumption: before the flexible system was introduced, the pension system had operated with a mandatory retirement age $R$ for $T$ years, and the system was in balance [(1)]:

$$
T b=\tau S w, \quad b=b(R) .
$$


(It would be more precise but too complicated to distinguish the rigid system's parameters as $R^{*}$ etc.)

The government introduces a limited flexible system in the year $t=1$ : the minimum retirement age is 1 year lower than the FRA: $R_{\mathrm{m}}=R-1$. The new cohorts retire at the minimum age: $R^{\prime}=R-1$, implying $S^{\prime}=S-1$ and $T^{\prime}=T+1$. Then the reduced benefit is equal to

$$
b^{\prime}=\frac{\tau(S-1) w}{T+1} .
$$

What additional costs arise during the transition? For simplicity, we assume that the contribution rate remains invariant, and the temporary deficit is financed by the budget. We start with the determination of the first year's costs $Z_{1}$, which is the sum of the missing contribution of the early retirees and their advanced benefits, i.e., using (4)

$$
Z_{1}=\tau w+b^{\prime}=\frac{S+T}{T+1} \tau w=\frac{1+\rho}{1+\rho \mathrm{S}} S \tau w,
$$

where $\rho=T / S$ denotes the old-age dependency ratio and $S \tau w$ is the original annual pension contribution (and expenditures).

We shall show that the annual transition costs $\left(Z_{t}\right)_{t=1}^{T+1}$ form a finite arithmetic series. In fact, every year, one old pensioner dies with $b$ and one new pensioner enters with $b^{\prime}$. Using the formulas for old and new benefits (1) and (4), the change in the costs arising in the year $t$ is equal to

$$
\Delta Z=Z_{t}-Z_{t-1}=b^{\prime}-b=\frac{S-1}{T+1} \tau w-\frac{S}{T} \tau w=-\frac{S+T}{T(T+1)} \tau w=-\frac{1}{T} Z_{1} .
$$

Then (6) yields

$$
Z_{t}=Z_{1}-(t-1) \Delta Z=Z_{1}\left(1-\frac{t-1}{T}\right), \quad t=1, \ldots, T+1 .
$$

Finally, we calculate the total costs of transition:

$$
C=\sum_{t=1}^{T} Z_{t}
$$

Inserting (5) and (7) into (8), and applying the formula for the sum of the arithmetic series:

$$
C=\tau \frac{(S+T) w}{T} \frac{T}{2}\left(\frac{1}{T+1}+\frac{T}{T+1}\right)=\tau \frac{(S+T) w}{2} .
$$

We shall relate this quantity to the original annual pension expenditures $(\tau S w)$ :

$$
C=\frac{1+\rho}{2} \tau S w
$$


If $\rho=0.4$, then according to (5), the first-year deficit is equal to $(1+0.4) /(1+16)=8.2 \%$ of the annual expenditures, while according to (10), the total costs of transition are equal to $(1+0.4) / 2=70 \%$ of the original annual expenditures.

It is evident that the starting as well as the total transitory costs are significant. They would be even higher if we allowed for earlier retirement, 2 or 3 years below the FRA and if the workers chose them. Here we present a simple estimate for a 2-year reduction. Calculating with double years, $R^{\prime \prime}=63 / 2$, then $S^{\prime \prime}=20$ and $T^{\prime \prime}=8, w^{\prime \prime}=2 w$, i.e., $C^{\prime \prime}=2 C$, the total costs would be double the 1-year reduction.

Of course, in reality, not everybody retires as soon as possible; there are even workers who delay retirement beyond the FRA. However, to open the window of opportunity down is much easier than to open it up. For example, if the widths of the window are equal to 3 years, then everybody can retire at 62 . However, those who wanted to retire at 68 but were forced to retire at 65 cannot return to work at age 66. Opening the window in both directions requires time. It is conceivable that the opening should be step-wise: $R_{\mathrm{m}}(2)=64, R_{\mathrm{m}}(4)=63$ and $R_{\mathrm{m}}(6)=62$ years.

We note that it is possible to consider a contribution rate which balances the pension system every year but it would complicate (1), namely in its numerator, $\tau S$ would be replaced by $\tau_{t+1}+\ldots+\tau_{t+S}$. We also neglected the variance of individual life expectancies. Furthermore, workers may die between minimum and maximum retirement ages; therefore, the expected remaining life expectancy $D_{R}-R$ is higher than our $D-R$, but we skip this complication, too. Our model would be even more complex if we took into account the fragmentation of careers, the variances of earnings of the remaining life expectancies, and of the cohort sizes. Here we would need serious empirical research. I can only cite Péter Vékás's information: in Hungary, the remaining life expectancy at 60 is equal to about 20 years, and its standard deviation is almost 10 years.

\section{Model with Increasing Real Wage}

If we relaxed our very strong assumptions, the quantitative results would change. In this paper, we only relax one assumption: time-invariant real wage is replaced by time-invariant real wage growth rate. The results remain valid qualitatively. Reflecting the Hungarian specifics, the cohorts' benefits in progress remain age-invariant in real terms but the initial benefits and the real wages increase with time. We shall see that our cost estimates basically remain correct.

Again, we start the analysis with the quasi-stationary version: $R_{t}=R$, and only after finishing it shall we turn to the dynamic model: $R^{\prime}=R-1$. 


\subsection{Quasi-stationary model}

We shall need the real wage dynamic:

$$
w_{t}=w_{0} g^{t}
$$

where $g$ stands for the real growth coefficient $(=1+$ growth rate). We shall see $((15)-(16)$, also Simonovits, 2020) that due to the economy of indexing of benefits in progress to prices, the initial pension should be corrected upward, by the imputed contribution rate $\tau_{g}$ :

$$
b_{t}=\frac{\tau_{g} S w_{t}}{T} .
$$

Since the initial benefit granted in the year $t$ retains its real value as benefit in progress for the next $T-1$ years, the cross-sectional balance condition in the year $t$ is as follows:

$$
\tau S w_{t}=\sum_{i=0}^{T-1} b_{t-i}
$$

Inserting (11) - (12) into (13) implies

$$
\tau S w_{t}=\frac{\tau_{g} S w_{t}}{T} \sum_{i=0}^{T-1} g^{-i}
$$

Simplifying (14) and using the formula for the sum of the geometric series implies

$$
\tau_{g}=\tau T \frac{1-g^{-1}}{1-g^{-T}} \quad g>1 .
$$

Introducing notation

$$
T_{g}=\frac{1-g^{-T}}{1-g^{-1}}
$$

and inserting (15) into (12) yields

$$
b_{t}=\frac{\tau S w_{t}}{T_{g}} .
$$

Comparing (16) to (1), one can see that $T_{g}$ stands for the "reduced duration of retirement" due to price indexation. Question: How can the government guess the future real wage growth rate ahead? Answer: The government can only forecast it and rely on buffer stocks in corrections (Sweden). 


\subsection{Dynamic model}

Repeating the introduction to 3.2, we analyse the scenario of reducing the retirement age while the real wages increase. We assume again that between years -15 and 0 , a mandatory retirement age of 65 was operating, but the real wages grew exponentially and the benefits in progress kept their real values. What happens during the transition towards a flexible system? Generalizing the story of the previous section, we still assume that the contribution rate remains constant and the transitional deficit is financed by the government.

Again, from the year $t=1$, flexible retirement is introduced: $R_{\mathrm{m}}=R-1$. In an extreme case, in the new system everybody retires at the minimum age: $R^{\prime}=R-1$. Then $S^{\prime}=S-1$ and $T^{\prime}=T+1$. We present the initial benefits, but now with rising real wages:

$$
b_{0}=\frac{\tau w_{0} S}{T_{g}} \text { and } b_{t}=\frac{\tau w_{t}(S-1)}{T_{g}+g^{-T}}=b_{1} g^{t-1}, \quad t=1, \ldots, T+1 .
$$

It is worth directly calculating the first year's deficit, which is the sum of the missing contributions of the freed cohort and the newly awarded benefits:

$$
Z_{1}=\tau g w_{0}+\tau \frac{S-1}{T_{g}+g^{-T}} w_{0} g .
$$

To find the general solution, we need the time-varying average benefits (see (14)):

$$
\bar{b}_{t}=\frac{\bar{b}_{1}\left(1+\ldots+g^{t-1}\right)+b_{0}\left(1+\ldots+g^{-T+t}\right)}{T+1}, \quad t=1, \ldots, T+1
$$

and $b_{T+1}=\tau(S-1) w_{0} g^{T+1} /(T+1)$.

The costs arising during the transition are given by the generalizations of (6) and (7). We display the cumulated costs as well:

$$
C_{t}=\sum_{s=1}^{t} Z_{s}
$$

Numerical example. It would be useless to the derive analytical formulae such as (5) and (10); therefore, we only present the numerical paths of the initial benefits in terms of the total wage compensation in the year $0: w_{0}=1$, the annual and the accumulated costs, in terms of the original pension expenditures $B_{0} . R=65, R^{\prime}=64$ years, $g=1.02$. Table 5 displays that due to rising real wages, notwithstanding the actuarial reduction, the relative average pensions are rising, the relative annual costs converge to zero and the accumulated costs converge to $66 \%$, slightly lower than in the static case. 
Table 4: Average benefits, annual and cumulated costs (rising real wages)

\begin{tabular}{|c|c|c|c|}
\hline Year & $\begin{array}{c}\text { Average break } \\
\text { benefit }\end{array}$ & $\begin{array}{c}\text { Annual costs } \\
\text { / Original } \\
\text { expenditures }\end{array}$ & $\begin{array}{l}\text { Cumulated } \\
\text { costs / Original } \\
\text { expenditures }\end{array}$ \\
\hline$t$ & $\bar{b}_{t}$ & $Z_{t} / B_{0}$ & $C_{t} / B_{0}$ \\
\hline 0 & 0.500 & - & - \\
\hline 1 & 0.503 & 0.074 & 0.074 \\
\hline 2 & 0.510 & 0.070 & 0.143 \\
\hline 3 & 0.518 & 0.066 & 0.209 \\
\hline 4 & 0.526 & 0.062 & 0.271 \\
\hline 5 & 0.534 & 0.057 & 0.328 \\
\hline 6 & 0.542 & 0.053 & 0.381 \\
\hline 7 & 0.550 & 0.049 & 0.430 \\
\hline 8 & 0.558 & 0.044 & 0.474 \\
\hline 9 & 0.567 & 0.040 & 0.514 \\
\hline 10 & 0.576 & 0.035 & 0.549 \\
\hline 11 & 0.585 & 0.030 & 0.580 \\
\hline 12 & 0.594 & 0.026 & 0.605 \\
\hline 13 & 0.603 & 0.021 & 0.626 \\
\hline 14 & 0.613 & 0.016 & 0.642 \\
\hline 15 & 0.622 & 0.011 & 0.652 \\
\hline 16 & 0.632 & 0.005 & 0.658 \\
\hline 17 & 0.642 & 0 & 0.658 \\
\hline
\end{tabular}

Source: Own calculations

To see the sensitivity of our calculations just to the growth rate of the real wages, Table 5 displays the initial average benefits and costs and the accumulated costs, each in terms of the initial total wage for various rates. In addition to the undiscounted accumulated costs, we shall calculate the discounted one, where the discount factor is equal to the growth factor:

$$
C_{t}^{g}=\sum_{s=1}^{t} Z_{s} g^{-s}
$$


Calculating with an annual growth rate of $4 \%$, the initial benefit grows slightly, the initial, cumulated and discounted costs decrease by 20,12 and $30 \%$, respectively.

Table 5: Benefits, starting and cumulated costs for various growth rates

\begin{tabular}{c|c|c|c|c}
\hline $\begin{array}{c}\text { Growth } \\
\text { coefficient } \\
\text { of real wage }\end{array}$ & $\begin{array}{c}\text { Average } \\
\text { benefit }\end{array}$ & $\begin{array}{c}\text { Initial costs } \\
\text { / Original } \\
\text { expenditures }\end{array}$ & $\begin{array}{c}\text { Cumulated } \\
\text { costs / Original } \\
\text { expenditures }\end{array}$ & $\begin{array}{c}\text { Discounted } \\
\text { costs / Original } \\
\text { expenditures }\end{array}$ \\
\hline $\boldsymbol{g}$ & $\overline{\boldsymbol{b}}_{\mathbf{1}}$ & $\boldsymbol{Z}_{\mathbf{1}} / \boldsymbol{B}_{\mathbf{0}}$ & $\boldsymbol{C}_{\boldsymbol{t}} / \mathbf{B}_{\mathbf{0}}$ & $\boldsymbol{C}_{\mathbf{t}} / \mathbf{B}_{\mathbf{0}}$ \\
\hline 1.00 & 0.498 & 0.082 & 0.700 & 0.700 \\
\hline 1.01 & 0.500 & 0.078 & 0.679 & 0.639 \\
\hline 1.02 & 0.503 & 0.074 & 0.658 & 0.584 \\
\hline 1.03 & 0.505 & 0.070 & 0.637 & 0.534 \\
\hline 1.04 & 0.508 & 0.066 & 0.617 & 0.488 \\
\hline
\end{tabular}

Source: Own calculations

\section{Conclusions}

In mature market economies, flexible retirement harmonizes efficiency and fairness. For example, in the US, Germany and Sweden, it functions without any special limitation. The "same" system works in several ex-socialist economies, but with strict conditions. For example, in Czechia, one has to have to contribute at least 35 years to retire before reaching the FRA and the deduction is severe. These limitations seem to be excessive and judged so by OECD (2020, p. 26). In Slovakia, the actuarially reduced initial benefit has to reach the minimum wage, which is close to the average benefit. One Polish government raised both FRAs, then another renounced the long-term equalization of female and male FRAs and reduced them to the original values.

In Hungary, the early retirement rules applied too low deductions before 2009. For example, between 2003 and 2007, the female FRA rose from 59 to 61, but the effective retirement age remained the same: around 57.5. Therefore, it was correct to raise the deductions in 2009. The elimination of flexibility from 2012, however, was a clear mistake. After a decade's freeze, it is worth introducing an actuarially fair retirement system, but this involves non-negligible temporary costs for two decades. The costs can be diminished by phasing out the otherwise popular Females40 scheme, but it is quite demanding politically. These strange combinations of loose and rigid retirement age policies are far from being socially optimal but their replacement with a truly flexible system looks politically difficult. 
In contrast to previous studies (e.g., Fabel, 1994; Diamond, 2003; Eső and Simonovits, 2002), now we do not study how the government chooses the pension rules and how the workers react to them. Following others, the current paper neglects the impact of indexation on retirement decision. Simonovits (2019) and (2020) suggest that with respect to price indexation, the otherwise superior wage indexation weakens the incentives to delay retirement. I only aimed to extend the static analysis to dynamic.

I tried to estimate these costs in a simplest model. Better models can involve more realistic assumptions, extending their validity to other, partially flexible retirement systems as well. The decision to introduce early retirement with actuarially fair deductions has to be made by the corresponding governments.

\section{Appendix}

\section{Welfare provided by flexible retirement}

In the main part of the paper, we have not analysed the welfare provided by flexible retirement. To make up for this omission, we have to introduce utilities. (In this Appendix, constant real wages are assumed.) We choose the simplest utility function:

$$
U[R]=(R-Q)[\log ((1-\tau) w)-\theta]-\varphi\left(R-R_{\mathrm{m}}\right)_{+}+(D-R) \log b(R),
$$

where the parameters $\theta$ and $\varphi$ represent the labour disutility of one year's work during the whole interval $[Q, D]$ and the final interval $\left[R_{\mathrm{m}}, D\right]$, respectively; the subindex + refers to the positive part of a real wage and $b(R)$ is defined in (1). (Implicitly, we fixed the contribution rate $\tau$, because there is a widespread opinion that it should not be raised further.) Evidently, the greater the $\theta$ and $\varphi$, the earlier the worker wants to retire. Since the numerical value of the utility function has no direct economic meaning, we shall rely on the relative efficiency or equivalent consumption variation, defined as follows. This is a real number $\varepsilon$; multiplying both the wage and the benefit by it, the rigid system $\left(R^{*}\right)$ provides the same utility as the flexible system $(R)$ without multiplication. (Here we follow the precise notation, which we mentioned below (3), forsaken until now.) Using the notation

$$
U(R, \varepsilon)=(R-Q)[\log ((1-\tau) w \varepsilon)-\theta]-\varphi\left(R-R_{\mathrm{m}}\right)_{+}+(D-R) \log (b(R) \varepsilon)
$$

the relative efficiency satisfies the following implicit equation:

$$
U\left(R^{*}, \varepsilon\right)=U(R, 1) .
$$

Using (A.2), a simple calculation yields 


$$
U(R, \varepsilon)=U(R, 1)+(D-Q) \log \varepsilon,
$$

i.e., (A.3) implies

$$
U\left(R^{*}, 1\right)+(D-Q) \log \varepsilon=U(R, 1) .
$$

Hence, the explicit formula for the relative efficiency is

$$
\varepsilon=\exp \left\{\left[U(R, 1)-U\left(R^{*}, 1\right)\right] /(D-Q)\right\} .
$$

Adopting the figures in Table 5, Table A1 shows the relative efficiency for $\varphi=0.1$ with various $\theta$ s. In Column 3, $\theta_{1}=2$, characterizing those workers with high labour disutility, who gain with early retirement. As can be seen, the optimal retirement age (italicized) $R^{\circ}=63$ raises utility by $0.4 \%$ above that of the rigid $65^{\text {th }}$ year, but the real loss of utility arises with higher age. In Column $4, \theta_{2}=1.8$ represents those workers, with medium labour disutility, for whom the optimal retirement age is just equal to the FRA. In Column 5, $\theta_{3}=1.5$ stands for those workers, with low labour disutility, who gain with the delay: $R^{\circ}=67$ yields welfare $0.5 \%$ higher than the rigid 65 , but the real loss of welfare arises for forced early retirement.

Table A1: Relative efficiency for early, normal and late retirement: $\boldsymbol{\tau}=\mathbf{0 . 2}$

\begin{tabular}{l|c|c|c|c}
\hline \multirow{2}{*}{$\begin{array}{l}\text { Effective } \\
\text { retirement } \\
\text { age }\end{array}$} & $\begin{array}{c}\text { Benefit } \\
\text { / Gross wage }\end{array}$ & high & medium & low \\
\cline { 2 - 5 } & $\boldsymbol{b} / \boldsymbol{w}$ & $\boldsymbol{\varepsilon}_{1}$ & $\boldsymbol{\varepsilon}_{\mathbf{2}}$ & $\boldsymbol{\varepsilon}_{\mathbf{3}}$ \\
\hline $\mathbf{R}$ & 0.389 & 1.003 & 0.992 & 0.976 \\
\hline $\mathbf{6 2}$ & 0.422 & 1.004 & 0.997 & 0.986 \\
\hline $\mathbf{6 4}$ & 0.459 & 1.003 & 0.999 & 0.994 \\
\hline $\mathbf{6 5}$ & 0.500 & 1.000 & 1.000 & 1.000 \\
\hline $\mathbf{6 6}$ & 0.547 & 0.995 & 0.998 & 1.004 \\
\hline $\mathbf{6 7}$ & 0.600 & 0.987 & 0.995 & 1.005 \\
\hline $\mathbf{6 8}$ & 0.662 & 0.978 & 0.988 & 1.004 \\
\hline
\end{tabular}

Source: Own calculations

To see the impact of the low contribution rate, as in Estonia, we repeat the calculations with $\tau=0.16$. Since lower pensions imply later retirement, we change the retirement age 
between 64 and 70 years. Keeping the other parameters, we see that the optimal retirement ages rise to 65,67 and 69 years, respectively.

Table A2: Relative efficiency for early, normal and late retirement: $\boldsymbol{\tau}=\mathbf{0 . 1 6}$

\begin{tabular}{l|c|c|c|c}
\hline \multirow{2}{*}{$\begin{array}{l}\text { Effective } \\
\text { retirement } \\
\text { age }\end{array}$} & $\begin{array}{c}\text { Benefit } \\
\text { / Gross wage }\end{array}$ & high & medium & low \\
\cline { 2 - 5 } $\boldsymbol{R}$ & $\boldsymbol{b} / \boldsymbol{w}$ & $\boldsymbol{\varepsilon}_{\mathbf{1}}$ & $\boldsymbol{\varepsilon}_{\mathbf{2}}$ & $\boldsymbol{\varepsilon}_{\mathbf{3}}$ \\
\hline $\mathbf{6 4}$ & 0.367 & 0.998 & 0.995 & 0.989 \\
\hline $\mathbf{6 5}$ & 0.400 & 1.000 & 1.000 & 1.000 \\
\hline $\mathbf{6 6}$ & 0.437 & 1.000 & 1.003 & 1.009 \\
\hline $\mathbf{6 7}$ & 0.480 & 0.997 & 1.004 & 1.015 \\
\hline $\mathbf{6 8}$ & 0.529 & 0.992 & 1.003 & 1.019 \\
\hline $\mathbf{6 9}$ & 0.587 & 0.985 & 0.999 & 1.021 \\
\hline $\mathbf{7 0}$ & 0.655 & 0.976 & 0.993 & 1.020 \\
\hline
\end{tabular}

Source: Own calculations

\section{References}

Barr, N. (2006). Pensions: Overview of the Issues. Oxford Review of Economic Policy, 22(1), 1-14, https://doi.org/10.1093/oxrep/grj001

Barr, N., Diamond, P. A. (2008). Reforming Pensions: Principles and Policy Choices. Oxford: Oxford University Press. ISBN 9780195311303.

Benitez-Silva, H., Demiralp, B., Liu, Z. (2009). Social Security Literacy and Retirement Well-Being. University of Michigan. Michigan Retirement Research Center Research Paper No. WP 2009-210, https://doi.org/10.2139/ssrn.1510309

Bottazzi, R., Jappelli, T., Padula, P. (2006). Retirement Expectations, Pension Reforms, and their Impact on Private Wealth Accumulation. Journal of Public Economics, 90(12), 2187-2212, https://doi.org/10.1016/j.jpubeco.2006.03.005

Breyer, F., Hupfeld, S. (2009). On the Fairness of Early Retirement Provision. German Economic Review, 11(1), 60-77, https://doi.org/10.1111/j.1468-0475.2009.00464.x

Chlon-Dominczak, A. (2019). Impact of Retirement Age Changes on the Old-age Pension Take up in Poland after 1990. Ubezpieczenia Spoleczne. Teoria i praktyka, 3, 41-65.

Chlon-Dominczak, A., Chybalski, F., Rutkowski, M. (2021). The Retirement Age and the Pension System, Labor Market and the Economy. mBank. Case Seminar Proceedings No. 167. 
Czegledi, T., Simonovits, A., Szabo, E., et al. (2017). What is Wrong with the Hungarian Pension Rules? Acta Oeconomica, 67(3), 359-387, https://doi.org/10.1556/032.2017.67.3.4

Diamond, P. A. (2003). Taxation, Incomplete Markets and Social Security. Cambridge, MA: MIT Press. ISBN 9780262042130.

Eso, P., Simonovits, A. (2002). Designing Optimal Benefit Rules for Flexible Retirement. North Western University. Discussion Papers No. 1353.

Eso, P., Simonovits, A., Toth, J. (2011). Designing Benefit Rules for Flexible Retirement: Welfare and Redistribution. Acta Oeconomica, 61(1), 3-32, https://doi.org/10.1556/ aoecon.61.2011.1.2

European Commission (2021). Aging Report. Brussels: European Commission.

Fabel, O. (1994). The Economics of Pensions and Variable Retirement Schemes. New York: Wiley.

Fazekas, K., Elek, P., Hajdu, T., (eds) (2020). Hungarian Labor Market. Budapest: Institute of Economics, Centre for Economic and Regional Studies.

Gál, R. I., Radó, M. (2020). Labor Market Participation and the Postponed Retirement in Central and Eastern Europe, in Holzmann, R., Palmer, E., Palacios, R., et al., eds., Progress and Challenges of Nonfinancial Defined Contribution Pension Schemes: Volume 1. Addressing Marginalization, Polarization, and the Labor Market, pp. 371-398, https://doi.org/10.1596/978-1-4648-1453-2_ch16

Gruber, J., Wise, D. A., (eds) (1999). Social Security and Retirement around the World. Chicago: University of Chicago Press. ISBN 9780226310114.

Gustman, A. L., Steinmeier, T. L. (2005). Imperfect Knowledge, Retirement and Saving. Industrial Relations, 44, 373-395.

Holzmann, R., Palmer, E., Palacios, R., et al., (eds) (2020). Progress and Challenges of Nonfinancial Defined Contribution Pension Schemes : Volume 1. Addressing Marginalization, Polarization, and the Labor Market. Washington, DC: World Bank.

Marosi, J., Molnar, D. L. (2018). Mortality of Old-age Pensioners (Hungarian). Statistical Review, 61, 5-26.

OECD (2020). OECD Review of Pension Systems: the Czech Republic. Paris: Organisation for Economic Co-operation and Development.

Palmer, E., Konberg, B. (2020). The Swedish NDC Scheme: Success on Track with Room for Reection, in Holzmann, R., Palmer, E., Palacios, R., et al., eds., Progress and Challenges of Nonfinancial Defined Contribution Pension Schemes: Volume 1. Addressing Marginalization, Polarization, and the Labor Market, pp. 27-50, https://doi.org/10.1596/978-1-4648-1453-2_ch2

Simonovits, A. (2003). Modeling Pension Systems. Oxford: Palgrave Macmillan. ISBN 978-1-4039-3845-9.

Simonovits, A. (2006). Optimal Design of Old-Age Pension Rule with Flexible Retirement: The Two-Type Case. Journal of Economics, 89(3), 197-222, https://doi.org/10.1007/ s00712-006-0196-4 
Simonovits, A. (2019). The Boomerang of Female40: Seniority Pensions in Hungary, 2011-2018. European Journal of Social Security, 21(3), 262-271, https://doi. org/10.1177/1388262719869527

Simonovits, A. (2020). Indexing Public Pensions in Progress toWages or Prices. Central European Journal of Economic Modelling and Econometrics, 12(2), 171-194.

Soosaar, O., Puur, A., Leppik, L. (2021). Does Raising the Pension Age Prolong Working Life? Evidence from Pension Age Reform in Estonia. Journal of Pension Economics and Finance, 20(2), 317-335, https://doi.org/10.1017/S1474747220000244 